\title{
EL DIÁLOGO INTERCULTURAL COMO MÉTODO PARA ARTICULAR UNA EXPERIENCIA ENTRE ESTUDIANTES DE BRASIL Y EL REINO UNIDO
}

\author{
Jorge Alejandro Santos (UBA)* \\ https://orcid.org/0000-0002-9081-5881 \\ Cláudia Battestin (UNOCHAPECÓ)** \\ https://orcid.org/0000-0001-7871-9275 \\ Darren R. Reid (Univesity Conventry)*** \\ https://orcid.org/0000-0002-5785-1071
}

\section{RESUMEN}

El artículo presenta una experiencia de diálogo intercultural a través de una clase compartida entre estudiantes de profesorado brasileños del pueblo Kaingang y estudiantes de historia del Reino Unido. Está inspirada en la propuesta de la filosofía intercultural que postula al diálogo entre culturas como método para articular un proyecto alternativo al proceso de globalización actual, sustentado en la diversidad de las culturas entendidas como reservas de humanidad capaces de brindar recursos para una mundialización solidaria, basada en la cooperación entre pueblos y culturas. La construcción de este diálogo requiere de acciones y propuestas concretas que lleven adelante lo meramente enunciado filosóficamente. Creemos que el ámbito educativo, y en especial la educación y la escuela indígena, es un espacio especialmente adecuado para articular el diálogo intercultural de manera práctica y concreta. Por eso además de presentar la experiencia se evalúan cualitativamente sus resultados, mostrando el impacto positivo que tuvo en los dos grupos que participaron en ella.

Palabras clave: Educación. Diálogo. Interculturalidad. Indígena. Kaingang.

\section{ABSTRACT}

\section{INTERCULTURAL DIALOGUE AS A METHOD FOR ARTICULATING AN EXPERIENCE BETWEEN STUDENTS FROM BRAZIL AND THE UNITED KINGDOM}

The article presents an experience of intercultural dialogue through a class

\footnotetext{
* Pós-Doutorando en Educación por Universidade Comunitária da Região de Chapecó (Unochapecó). Doctor en Filosofía por Universidad de Buenos Aires (UBA). Professor da Facultad de Filosofía y Letras da Universidad de Buenos Aires e Professor Adjunto da Faculdade de Ciências Econômicas da Universidad Nacional de Lomas de Zamo. E-mail: jorgesantosuba@gmail.com

** Doctora en Educación por Universidad Federal de Pelotas (UFPel - Brasil). Profesora del Departamento de Humanidades y Ciências Jurídicas y del programa de Posgrado en Educación por Universidade Comunitária da Região de Chapecó (Unochapecó - Brasil). E-mail: claudiabattestin@hotmail.com

*** Doctor en Historia por University of Dundee (Reino Unido). Profesor y Director del curso de Historia de la Univesity Conventry (Reino Unido). E-mail: ab8203@coventry.ac.uk
} 
shared among Brazilian students of the Kaingang people and history students of Coventry University in the United Kingdom. It is inspired by the proposal of intercultural philosophy that postulates the dialogue between cultures as a method to articulate an alternative project to the current process of globalization, based on the diversity of cultures understood as reserves of humanity capable of providing resources for a globalization based on cooperation between peoples and cultures. The construction of this dialogue requires concrete actions and proposals that carry forward what is merely stated philosophically. We believe that the educational field, in particular the indigenous school, is an excellent space to articulate the intercultural dialogue in a practical and concrete way. Therefore, in addition to presenting the experience, its results are evaluated qualitatively, showing the positive impact it had on the two groups that participated in it.

Keywords: Education. Dialogue. Interculturality. Indigenous. Kaingang.

\section{RESUMO}

\section{O DIÁLOGO INTERCULTURAL COMO MÉTODO PARA ARTICULAR UMA EXPERIÊNCIA ENTRE ESTUDANTES DO BRASIL E REINO UNIDO}

0 artigo apresenta uma experiência de diálogo intercultural por meio de uma aula compartilhada entre estudantes brasileiros do povo Kaingang e estudantes de história da Universidade de Coventry, no Reino Unido. É inspirado pela proposta da filosofia intercultural, que propõe o diálogo entre culturas como forma de articular um projeto alternativo para o atual processo de globalização, com base na diversidade de culturas entendida como reservas de humanidade capazes de fornecer recursos para uma globalização da solidariedade, com base na cooperação entre povos e culturas. A construção desse diálogo requer ações concretas e propostas que levem adiante o que é meramente declarado filosoficamente. Acreditamos que o campo educacional, especialmente a educação e a escola indígena, é um excelente espaço para articular o diálogo intercultural de maneira prática e concreta. Portanto, além de apresentar a experiência, seus resultados são avaliados qualitativamente, mostrando o impacto positivo que teve nos dois grupos que participaram.

Palavras-chave: Educação. Diálogo. Interculturalidade. Indígena. Kaingang.

\section{Introducción}

Buscar elucidar momentos que pueden promover el aprendizaje y la socialización entre saberes, es lo que impulsiona esta escrita. Y fue por medio de un proyecto entre la Universidad de Coventry del Reino Unido de Gran Bretaña y la Universidad Comunitaria de la Región de Chapecó, Santa Catarina, Brasil, que iniciaron los diálogos sobre cultura entre las dos instituciones. Este articulo parte de esta experiencia intercultural cuyo objetivo es presentar como el diálogo entre las culturas puede colaborar para una educación capaz de crear posibilidades de cambios y pensamientos. Pero, para que haya diálogo necesita haber horizontalidad en la comunicación entre los individuos que forman parte y entre las culturas que en él intervienen. Es evidente que los individuos y las culturas que entran en diálogo no se encuentran de 
hecho en condiciones de igualdad, sino que, estas condiciones, deben ser construidas y cuidadas. En esta situación, el diálogo se originó mediante el uso de recursos tecnológicos con los estudiantes del grado de licenciatura intercultural indígenas (Brasil) y con los estudiantes de grado de historia (Reino Unido), generando, espacios de sensibilización y curiosidad por las culturas de ambos. Pero, lo que más llamo la atención, fue la curiosidad de los estudiantes de Historia de Universidad de Coventry Unido por la cultura indígena de Brasil.

Adriana Puiggrós (1996) sostiene que desde tiempos de la conquista fueron objeto de forma particular de dominación caracterizada por la ausencia del registro de los discursos de los indígenas, por la resistencia férrea de España y Portugal a cualquier tipo de penetración cultural y por la identificación negativa de los indígenas por el desconocimiento de la lengua y la religión de los conquistadores (más que por el conocimiento de la propia), señalándolos como 'no educados' y sospechados de 'incapaces de educación'. Estos preconceptos según la autora, aún se encuentran presentes y es común identificar a la población indígena como "no educada" por el desconocimiento de la cultura o lengua occidental, mas que por el propio conocimiento de su cultura y de su lengua. El trabajo de las Licenciaturas Interculturales indigenas de la Unochapecó donde esta experiencia se inserta, tiene como objetivo revertir esa concepción poniendo en el centro de la formación de profesores indígenas la valorización de la propia cultura, lengua e identidad.

Desde el año 2009 la Unochapecó tiene un programa de formación de profesores indígenas a fin de satisfacer la demanda de profesionales capacitados pertenecientes a las propias comunidades para desempeñarse dentro de ellas en el área de educación básica y media. El programa a sido exitoso en varios aspectos, ha logrado formar un número importante de profesores que se desempeñan profesionalmente cumpliendo su objetivo principal. Para esto tuvo que solucionar algunos inconvenientes específicos, en especial tuvo que desarrollar una estrategia para disminuir la evasión de estudiantes indígenas de la educación universitaria. La principal estrategia para reducir la evasión de estudiantes, como lo señalamos en artículos anteriores (SANTOS; PIOVENZANA; NARCISO, 2018), fue dictar el curso de Licenciatura Intercultural dentro de las Tierras Indígenas. Es decir, en vez de que los estudiantes salgan de la tierra indígena hacia la ciudad, la universidad y sus profesores van a las tierras indígenas a dictar sus cursos.

En estudios anteriores sostuvimos que la causa de la evasión se debía principalmente a lo que conceptualizamos como tres fronteras: físicas, culturales y económicas. Sintéticamente las fronteras físicas se refieren a las dificultades de trasladarse desde la zona rural donde se encuentras las tierras indígenas hasta la ciudad, con fronteras culturales nos referimos a él preconcepto que aún existe sobre la población indígena y el poco conocimiento de los profesores universitarios de la cultura, el contexto y las costumbres de esa población. Finalmente, la frontera económica existe en el sentido de que la población se encuentra entre los sectores de menos recursos económicos de la sociedad brasilera. Ante estas fronteras, las políticas pedagógicas que pretendían formar profesores indígenas en las mismas instituciones y con similar pedagogía con las que se forman profesores no indígenas se mostraban ingenuas y descontextualizadas, incapaces de enfrentar la envergadura real del problema. La estrategia diseñada por la Unochapecó con apoyo financiero de la Secretaría de Educación del Estado de Santa Catarina fue exitosa y consiguió revertir la evasión de los estudiantes indígenas de las aulas universitarias.

Otro de los éxitos del programa consistió en lo que llamamos la alfabetización intercultural de los profesores que participan del proyecto. Porque, paradójicamente quien más experiencia intercultural tiene en este contexto es estudiante indígena que siempre ha vivido entre dos culturas y ha tenido que mediar cons- 
tantemente entre las prácticas, costumbres y lenguajes de una y otra. En cambio, para los profesores, habituados a la educación en el contexto universitario tradicional, ir a enseñar en una escuela de una comunidad indígena implica reaprender el contexto y realizar el esfuerzo de adquirir la práctica de la mediación cultural, con el cuidado de no hacerlo de manera colonial sino al contrario descolonizando sus propias prácticas pedagógicas (SANTOS; PIOVENZANA; NARCISO,2018).

Sin embargo, la estrategia diseñada para el programa también implica algunas dificultades, como el riesgo a lo que llamamos "endogamia educativa". En el sentido de que por dictarse dentro de la tierra indígena el curso tiene la ventaja de reducir drásticamente la evasión, pero la desventaja de que los alumnos no transitan la experiencia de estar en el contexto universitario que, si bien suele resultar hostil a la cultura indígena, brinda ciertas habilidades importantes para un profesor de escuela inicial o media, sobre todo en el caso de que ocupe cargos directivos o de gestión dentro de las escuelas indígenas. Es importante para los profesores más allá del aprendizaje de contenidos, el aprendizaje práctico del funcionamiento del sistema educativo fuera de la tierra indígena a fin de poder convertirse en gestores, articuladores y mediadores de las demandas educativas de las comunidades a las que pertenecen frente a los diferentes niveles de gestión estatal, municipal, provincial y nacional. Por lo tanto, se diseñaron algunas estrategias para que el tránsito entre la educación en la tierra indígena y la dictada en la universidad en su cede urbana no quedasen aisladas. En este artículo expondremos una experiencia que tiene como fin vincular a los estudiantes con el contexto educativo no indígena y que va más allá del contexto nacional y regional: clase compartida con los estudiantes de la Universidad de Coventry del Reino Unido de Gran Bretaña.

Esta experiencia de diálogo tiene también otro lado con otro sentido y objetivos (dia-logo señala la existencia de dos logos, dos razones o sentidos que entran en contacto). Desde el lado inglés participaron estudiantes de la Universidad de Coventry en su mayoría de la graduación de historia matriculados en un módulo sobre racismo y resistencia en América. Estos estudiantes conocían a través de textos científicos la historia de la colonización de América, principalmente de Norteamérica por su pasado como colonia Británica. Además, su idea sobre la población indígena americana suele estar formada las imágenes de la cultura popular que se da a través de medios de comunicación, documentales, películas o series de televisión. Pasar de ese conocimiento abstracto a un diálogo con personas reales, donde cada uno, en un marco de respeto y comprensión, puede hacer preguntas y reflexiones directas se transforma en una experiencia impactante.

En lo sucesivo el artículo hará una breve descripción del marco teórico en el que se desarrolla la experiencia objeto de este estudio, luego se referirá a las Licenciaturas Interculturales Indígenas de la Unochapecó y a la población kaingang para contextualizar la experiencia. Asimismo, describirá los caracteres e intereses de los estudiantes ingleses y los objetivos que los grupos pretendía alcanzar en el diálogo. Luego haremos una breve descripción de la experiencia y expondremos los resultados alcanzados evaluados a través de métodos cualitativos especialmente entrevistas y preguntas informales de los profesores a los participantes luego de la experiencia. En el apartado final se expondrán las conclusiones.

\section{Marco teórico-metodológico de la experiencia}

El marco teórico en el que se desarrolla la experiencia objeto de este artículo es la filosofía intercultural y la pedagogía freireana releída desde la perspectiva intercultural (SANTOS, 2017). Especificamente adherimos a la idea de Raul Fornet-Betancour (2000) que propone al diálogo intercultural como un método para 
articular un proyecto alternativo al proceso de globalización actual, sustentado en la diversidad de las culturas entendidas como reservas de humanidad capaces de brindar recursos para una mundialización solidaria, basada en la cooperación entre pueblos y culturas más que en el afán de competencia y dominación del otro.

El diálogo intercultural se postula como un proyecto para articular y generar una respuesta alternativa a la integración o asimilación de la alteridad en una supuesta 'cultura mundial' monoculturalmente predeterminada por occidente y sustentada en los procesos comerciales y financieros típicos de la globalización neoliberal. El diálogo respetuoso, empático, horizontal se propone como un instrumento para reorganizar en el mundo las relaciones entre culturas en base a la cooperación y de comunicación solidarias entre los diferentes universos culturales existentes en la humanidad. El diálogo intercultural así entendido implica un proyecto alternativo de convivencia y relación entre las culturas y los pueblos: darle la posibilidad a un mundo donde quepan muchos mundos.

Dentro de este marco de diálogo intercultural se recurre a algunas metodologías específicas. Los estudiantes de ambos grupos tendrán que decir quienes son, responder las preguntas del otro grupo y luego reflexionar, a partir de ellas, sobre la cultura de los otros y sobre la propia. Esto es interesante pues pueblos indígenas suelen ser los "etnografiados", es este tema inclusive, utilizamos como fuente los excelentes trabajos etnográficos de Veiga $(1994,2000)$ en los que describe la cultura kaingang. En el marco del diálogo, sin embargo, los estudiantes indígenas tienen un rol activo al presentarse, decir quienes son, describir su cultura con su propia vos y, asimismo, son activos al hacer preguntas al grupo de estudiantes europeos. Los estudiantes europeos tienen un rol equivalente. Veremos que los intercambios llevaron a los estudiantes a reflexionar sobre su propia cultura a la par de conocer y pensar la cultura del otro. Por lo que sin ser este artículo una autoetnografía, hay un cierto recurso al método autoetnográfico en la implementación del diálogo, entendido como estudio y descripción de un grupo social que se considera propio, ya sea por la pertenencia cultural, la ubicación socioeconómica, la ocupación laboral o el desempeño de alguna actividad específica (BLANCO, 2012).

Asimismo, una vez expuesta la experiencia se procederá a una evaluación cualitativa de la misma realizada a partir del análisis de conversaciones y preguntas informales realizadas a los participantes de la experiencia. El método cualitativo aplicado busca responder preguntas particulares que no se pueden cuantificar a fin de profundizar la comprensión de las causas y significados de las acciones humanas (MINAYO; GOMES; DESLANDES, 2002).

Retomando el marco teórico de la propuesta de diálogo intercultural surgen algunos interrogantes en torno a ella: ¿en qué ámbitos se dará este diálogo en concreto?, ¿entre quiénes?, ¿quién hará de interlocutor de las culturas?, ¿quiénes serán los representantes de ellas?

Hay que tomar conciencia de que el diálogo, del que tanto se presume, es absolutamente imposible si no se dan condiciones de igualdad. Es incluso, como sostiene Panikkar (2006), una afrenta hablar de diálogo a quien se está muriendo de hambre, a quien se le ha despojado de su dignidad humana o a quien ni siquiera sabe de qué estamos hablando, porque su sufrimiento o su diferente cultura lo incapacitan para ello.

En el contexto actual no sobran los espacios en que las condiciones mínimas para el diálogo estén dadas en tanto lo pensemos como una alternativa posible, concreta, realizable y capaz de disputar la presencia hegemónica de la globalización neoliberal.

El ámbito educativo, en especial la escuela, se presenta como uno de los espacios posibles donde el diálogo intercultural podría practicarse de manera concreta y en condiciones aceptables. Especialmente la escuela en las comunidades indígenas, los programas de 
formación de profesores indígenas en las universidades y particularmente las aulas de las Licenciaturas Interculturales Indígenas de la Unochapecó, nos dan un contexto adecuado para poner en práctica, de manera concreta y no meramente retórica el diálogo intercultural. En el caso que nos ocupa el diálogo se pone en práctica entre estudiantes indígenas kaingang, estudiantes de la universidad de Coventry ciudadanos de distintos países europeos y profesores latinoamericanos e ingleses que participaron de esta experiencia.

Somos conscientes de que frente a la dimensión del proceso globalizador esta propuesta alternativa es pequeña y humilde. Pero su carácter concreto, real y no meramente enunciativo la hacen muy valiosa y la convierten en un ejemplo que alienta la esperanza. Un grano de arena en el mar no es nada, pero es un grano de arena.

\section{Conociendo el pueblo Kaingang en el Oeste Catarinenese y las Licenciaturas Interculturales}

Los kaingang son la principal sociedad Ge del Brasil Meridional. Su territorio tradicional abarcaba los estados de São Paulo, de Paraná, Santa Catarina, Rio Grande do Sul y la provincia argentina de Misiones. Su economía se sustentaba en la caza, recolección, pesca y agricultura complementaria. Los primeros contactos registrados son de misioneros jesuitas españoles en el año 1626 que intentaron reducirlos sin éxito en la misión de Guairá. Desde ese primer contacto hasta la fecha el derrotero del pueblo Kaingang por su supervivencia es similar al de otros pueblos originarios de América, una historia de luchas y resistencias, negociaciones y acuerdos, adaptación a las nuevas realidades impuestas por la cultura nacional hegemónica. Una historia no exenta de contradicciones a la que no nos referiremos detalladamente aquí por exceder los estrechos objetivos de este artículo, remitimos a quien tenga interés en la cultura kaingang y su historia a trabajos de especialistas como Juracilda Veiga $(1994,2000)$

Actualmente, la población kaingang es de 50.000 personas aproximadamente en 25 áreas de reserva en los estados de São Paulo, Paraná, Santa Catarina y Rio Grande do Sul. Un número equivalente sobrevive en las periferias de las ciudades (FUNDAÇÃO NACIONAL DO ÍNDIO, 2010).

En el estado de Santa Catarina, la mayoría de las tierras demarcadas están en la región oeste, entre ellas la Aldea Toldo Chimbangue, donde se dicta la Licenciatura a la que concurren estudiantes de todas las aldeas cercanas. Actualmente la actividad principal de la población que vive en territorio kaingang es la pequeña agricultura de subsistencia. Muchos también se dedican a la venta de artesanías tradicionales en las ciudades y rutas de la región. Asimismo la zona es uno de los mayores polos alimenticios y agroindustriales de Brasil, por lo que muchos indígenas son contratados con sueldos mínimos por los frigoríficos como mano de obra de baja calificación en esa industria.

Vale recordar que los territorios indígenas (T.I) demarcados no son propiedad de las comunidades, el usufructo es otorgado para su subsistencia física y cultural, pero son territorios de la Unión. Por lo tanto, la posesión de la tierra es precaria incluso si ha sido demarcada.

Dentro de las T.I. actualmente hay escuelas de enseñanza básica y media. De acuerdo a la normativa que regula la educación indígena, la situación ideal es que los profesores que enseñan en la escuela dentro de los territorios pertenezcan a las comunidades ${ }^{1}$. Ante la falta de profesores pertenecientes a las comunidades del oeste catarinense, la Secretaría de Educación, Cultura y Deporte de Santa Catarina junto con la Unochapecó diseñaron las Licenciaturas Interculturales Indígenas que comenzaron a dictarse en 2009 con el objetivo de formar

1 A la normativa Federal se suma la regulación del Estado de Santa Catarina que en su Constitución (Art. 210) asegura a las comunidades indígenas el uso y la enseñanza en sus lenguas maternas, así como sus propios procesos de aprendizaje. 
profesores pertenecientes a las comunidades kaingang de la región. Para evitar la evasión de los estudiantes indígenas y atravesar las fronteras físicas, culturales y económicas citadas anteriormente, la estrategia fue que la universidad vaya a la tierra indígena con su programa de formación de profesores en vez de que el estudiante salga de la aldea. La estrategia fue exitosa en tanto la evasión se logró revertir alcanzando un $90 \%$ de la asistencia regular a los cursos. Sin embargo, la estrategia implicaba un riego de aislamiento de la comunidad educativa indígena del resto del sistema educativo. A fin de evitar este riesgo se realizan algunas clases y eventos especiales en la universidad, se organizaron eventos científicos y de extensión a los que los estudiantes indígenas asisten y experiencias de diálogo intercultural como la que exponemos en este estudio. Importante destacar que se formaron dos grupos de profesores indígenas, el primero entre los años 2009 y 2013 y el segundo entre 2014 y 2018. Para agosto de 2019, se ofrecerán 100 vagas para que los indígenas estudien en la licenciatura intercultural indígena

Los estudiantes indígenas que participaron de esta clase intercultural con estudiantes de Inglaterra pertenecen al segundo grupo. La clase se realizó el día 28 de febrero de 2019, una semana antes de la ceremonia de formación y entrega de diplomas. Era un período de receso de un curso que estaba prácticamente concluido por lo que solo requerimos la asistencia de miembros pertenecientes a las comunidades más cercanas a la ciudad de Chapecó.

Participaron estudiantes de la Aldea Kondá y de la Tierra Indígena Toldo Chimbangue. Lograr momentos de acercamiento con otras culturas es una forma de mostrar para el mundo a cultura Kaingang, según los informes de los estudiantes de indígenas.

Es importante señalar que los profesores de la Universidad de Coventry que participaron en la organización del diálogo, visitaron las tierras indígenas en ocasión de un workshop sobre desarrollo sustentable y gobernanza rea- lizado en la ciudad de Chapecó a mediados de 2018. Por lo que ya conocían a los estudiantes indígenas, sus escuelas y sus comunidades. El conocimiento personal fue un hecho importante para el éxito del diálogo, la existencia de una relación personal previa hace mucho más fácil la comunicación y el diálogo intercultural. Creemos que la experiencia no hubiera funcionado sin este paso previo. Todos los estudiantes que participaron conocían al profesor de Inglaterra y ya habían establecido una relación de empatía. Después de esta llegada, se organizó un documental sobre los Kaingang, que se extendió ampliamente entre los países (KEEPERS..., 2019). Este documental contribuyó para mostrar la historia y la cultura de este grupo étnico, pero, su trasfondo a presentado voces que claman por respecto frente a los preconceptos y exclusión.

\section{La dinámica de la clase compartida con los estudiantes de la Universidad de Coventry y Unochapecó}

Acerca de los estudiantes de la Universidad de Coventry es importante mencionar que no hubo estudiantes indigenas. Los mismos venían de Inglaterra, Irlanda del Norte, Francia y España, todos ellos en su último año de estudios de grado. La mayoría matriculados en el programa de historia a excepción de algunos matriculados en un curso de honor conjunto de Historia y Política. Ambos programas se caracterizan por su énfasis en el estudio de historia moderna (1492-2000), en especial las de los pueblos occidentales desde el año 1800. El grupo se encontraba cursando el módulo de enseñanza titulado "Racismo y resistencia en los Estados Unidos" donde se estudia las experiencias históricas de los colectivos indígenas nativoamericanos, afroamericanos, latinos y americanos originarios de Asia oriental en los EEUU desde 1814 a 1992. Se hizo especial hincapié en las experiencias de los indígenas americanos y 
afroamericanos. La filosofía de este módulo se resume en la siguiente tesis que intentó ser corroborada a lo largo del semestre: "las historias de las minorías raciales en las Américas no son historias de represión. Sino historias de cómo estos grupos la enfrentaron, lucharon y la superaron. Son historias de empoderamiento y no apenas historias de opresión."

Antes de la sesión de diálogo intercultural con los estudiantes kaingang, los estudiantes europeos conocían a los indígenas americanos a través de dos fuentes: la cultura popular, como el cine, la literatura y otras formas de medios de comunicación, y a través de sus estudios en la universidad. Ninguno conocía personalmente a algún integrante de un pueblo indígena americano y, como la mayoría de los europeos occidentales, gran parte de su conocimiento sobre estos pueblos estaba determinada por un entorno mediático que enfatiza sobre la experiencia y los estereotipos de los pueblos nativos norteamericanos.

El en curso que finalizó con la clase compartida y el diálogo con los estudiantes kaingang se intentó desconstruir esta imagen estereotipada que los estudiantes comparten con la población europea en general. Se analizó esta versión esterotipada proveniente del cine fundamentalmente norteamericano desde una perspectiva postcolonial. Se hizo especial hincapié en las formas en que los europeos y los estadounidenses de origen europeo proyectan imágenes, lugares e ideas comunes sobre los pueblos indígenas, independientemente de que sean o no apropiados.

Para la deconstrucción de tales tropos populares se colocaron las imágenes de los films en una tradición artística de varios siglos de duración, esto contribuyó a demostrar la naturaleza problemática del simbolismo que se asocia con los indígenas americanos. A través de las discusiones, los estudiantes pudieron comprender mejor las complejidades de las culturas e historias indígenas, así como las imágenes coloniales que dan forma a sus juicios previos sobre estos pueblos. En relación al pueblo Kaingang, se organizó un seminario especial en el que se les dio la oportunidad de hacer preguntas y se expusieron investigaciones y experiencias de sus profesores con ese pueblo. Luego, los estudiantes trabajaron en grupos pequeños, llevando a cabo discusiones sobre los tipos de ideas y conceptos que deseaban abordar en el encuentro. Así se definieron una serie de preguntas que se concentraron en los temas de identidad y cultura. Esas preguntas fueron:

a) ¿Qué piensan los brasileños no indígenas sobre los kaingang?

b) ¿Cómo te sientes acerca de la figura histórica, Kondá? ${ }^{2}$

c) ¿Qué quieren que la gente de Europa sepa sobre el pueblo Kaingang?

d) ¿Cuáles son las barreras que enfrentan los kaingang con respecto a su educación?

e) ¿Puedes darnos algunos ejemplos del folklore kaingang?

f) ¿Cuántos miembros de su comunidad hablan el idioma kaingang?

g) ¿De dónde vienen los kaingang?

h) ¿El sistema educativo en Brasil ayuda a empoderar a su comunidad?

Para los estudiantes, que provienen de diferente orígenes culturales y sociales, esta fue su primera oportunidad de dialogar directamente con alguien perteneciente a un pueblo indígena de América. El seminario les brindó una oportunidad única: las de participar y gestionar un diálogo dinámico e intercultural. En un mundo cada vez más globalizado, esta experiencia les proporcionó una oportunidad intelectual y humanamente emocionante, una globalización diferente que pone acento en el encuentro respetuoso y en el diálogo entre los pueblos, en la unión, el respeto, la empatía y la solidaridad, más que en los negocios, el comercio o las finanzas.

2 Jefe que da nombre a una de las comunidades kaingang del oeste de Santa Catarina. El grupo del cacique de Kondá fue derrotada por los colonizadores y usada para derrotar militarmente a otros grupos de indígenas, incluso kaingangs que aún no se habían adherido a la autoridad estatal. 
Importante destacar que, durante la dinámica con la que se organizó la clase compartida y el diálogo entre los estudiantes, tuvimos dos dificultades fundamentales: la distancia y la lengua. La distancia puede fácilmente resolverse con las condiciones tecnológicas actuales con una video-conferencia. Sin embargo, las Licenciaturas Interculturales Indígenas se dictan en las Tierras Indígenas donde las condiciones técnicas para una video-conferencia son totalmente insuficientes. No hay equipos técnicos ni existe conexión a internet mínimamente estable. Por eso se decidió hacer el diálogo desde lo campus de la universidad que cuenta con una sala con condiciones técnicas óptimas.

La dificultad logística consistió en llevar a los estudiantes desde las aldeas hasta la ciudad en el período de receso. Aunque parezca simple, no es un problema menor, pues el transporte desde la zona rural en ocasiones es sumamente dificultoso. Pero además la vida social, económica y cultural de la tierra indígena, tiene su dinámica, sus obligaciones y tareas que no son siempre postergables y una temporalidad, un sentido de la puntualidad y de los tiempos propicios (SANTOS; BATTESTIN; PIOVENZANA, 2018) no siempre compatible con la organización de una video-conferencia al modo en que acostumbramos en las universidades. A esto hay que sumarle el hecho de que muchos de los estudiantes indígenas era la primera vez que asistían o participaban de una videoconferencia.

A causa de estas circunstancias organizamos la llegada de los estudiantes indígenas a la universidad con algunas horas de anticipación, hicimos una pequeña reunión explicando la dinámica que habíamos pensado para el diálogo y les pedimos que escriban algunas preguntas que ya habían pensado para hacerles a los estudiantes europeos. Algunos se mostraron sorprendidos pues no habíamos conseguido explicar claramente, en las reuniones previas, la idea de la comunicación por videoconferencia y algunos esperaban encontrar a los alumnos europeos en persona, como lo habían hecho anteriormente con los profesores de Coventry cuando visitaron Brasil ${ }^{3}$. Sin embargo, rápidamente comprendieron la dinámica y lograron hacer una serie de preguntas sumamente interesantes.

a) ¿Cómo ven los europeos a las poblaciones indígenas americanas?

b) ¿Tienen población indígena en Europa?

c) ¿Qué saben de los kaingang?

d) ¿Por qué están interesados en nuestra cultura?

e) ¿Qué les interesa saber de nuestra cultura?

f) ¿Quieren oír nuestra lengua?

g) Al profesor que ya había visitado la tierra indígena ¿Cuál era su opinión sobre ella y qué enseñanza se llevó de su visita?

h) ¿Quieren saber de nuestras danzas y nuestras mitades clánicas?

Como vimos en el apartado anterior los estudiantes europeos tuvieron una clase de preparación previa, que incluyó un proceso de deconstrucción de su imagen sobre las poblaciones originarias de América. $Y$ esto es sumamente importante al momento de pensar un diálogo intercultural. Pues al contrario de lo que se supone la cultura occidental y quienes la integran (europeos o americanos de origen europeo) son quienes tienen menos experiencia y apertura intercultural. Fornet-Betancourt (2000) habla de que existe un extendido "analfabetismo intercultural" incluso entre profesores y estudiantes universitarios. En la experiencia de las Licenciaturas Interculturales esto fue notorio, uno de los resultados positivos de ellas fue la alfabetización intercultural de los profesores, que al tener que ir a enseñar a la

3 Junto con los estudiantes vinieron algunos familiares más jóvenes, que no son estudiantes de la Licenciatura. Es frecuente en el aula universitaria indígena la presencia de familiares, hijos o hermanos más jóvenes, que tiene que ver con el modo indígena de "educar", se educa participando, viendo como los mayores actúan, imitando a los que saben. Se trata de una forma de enseñanza más concreta que pone acento en la práctica y la imitación. Participaron del encuentro tres estudiantes de Kondá y uno del Toldo Chimbangue, más tres estudiantes jóvenes de nivel medio que esperamos recibir en los cursos universitarios cuando sean reabiertos. 
aldea indígena, aprenden in situ, un contexto cultural que ignoraban o desconocían.

En cambio, las poblaciones indígenas llevan siglos de contacto, aprendizaje, adaptaciones y de diseño de estrategias de supervivencia frente al avance de la cultura occidental sobre su propia cultura, su territorio y hasta sus propios cuerpos. Esto se hace evidente en el tema de la lengua: el diálogo se realizó a partir de la presencia de un traductor de inglés al portugués y viceversa. Los estudiantes de Brasil hablan la lengua kaingang además del portugués y, para la mayoría, es su lengua materna y de habla cotidiana en la aldea. Sin embargo, todavía no es posible hacer participar plenamente a la lengua kaingang del intercambio intercultural pues mientras ellos hablan dos lenguas (una europea y otra indígena,) los no-indígenas europeos o americanos solo hablan lenguas de origen europeo. Esta circunstancia hace evidente que la competencia intercultural de los estudiantes indígenas en mayor.

La dinámica del diálogo permite desconstruir el prejuicio colonial vigente desde los tiempos de la conquista europea en territorio americano que identifica al indígena como salvaje, no educado e ignorante por el desconocimiento de la lengua, cultura, ciencia y religión europea y nunca por el conocimiento de su propia lengua, cultura, ciencia y religión (PUIGGRÓS, 1996).

El diálogo se articuló entonces en de manera bilingüe en inglés y portugués con la asistencia de un traductor que la Unochapecó puso a disposición de la experiencia. Los estudiantes indígenas sin embargo querían hablar y mostrar su lengua a sus colegas ingleses, por lo que muchas veces formulaban las preguntas y/o respuestas en lengua kaingang y luego ellos mismos la traducían al portugués para ser nuevamente traducidas al inglés.

El intercambio resultó sumamente interesante, se trató de un diálogo dinámico y respetuoso que logró atravesar barreras lingüísticas, culturales y geográficas. Comenzó con una introducción y presentación de los grupos por parte de los profesores que coordinaron el encuentro y luego comenzó el diálogo a través de preguntas que se habían preparado. Si bien se había una lista por cada grupo, el diálogo tomó su propia dinámica y una respuesta llevó a otra pregunta sin seguir necesariamente el orden planeado de preguntas. Nos interesaba más la fluidez del diálogo que recorrer exhaustivamente la lista planeada. Además del traductor dos profesores de la Unochapecó y un profesor de la Universidad de Coventry oficiaron de mediadores y facilitadores del diálogo dado su conocimiento previo de los grupos y dinámica.

Los resultados fueron sumamente interesantes en especial por alguna serie de preguntas que sorprendieron a los participantes y los llevaron a repensar sus concepciones sobre el otro grupo y sobre todo sobre ellos mismos.

A causa de su extensión no podemos reproducir el diálogo de manera completa, por lo que optamos por resaltar las partes que consideramos más interesantes, atendiendo especialmente a la opinión de los estudiantes. Concluido el diálogo se realizaron en ambos grupos preguntas generales sobre el resultado de la experiencia y se recogieron las opiniones y sentimientos de los participantes.

Las preguntas de los estudiantes europeos estuvieron dirigidas a la relación de la población indígena y la no-indígena en el contexto brasilero, por un lado, y giraron en relación a la cultura propia del pueblo Kaingang por el otro.

Las preguntas de los estudiantes indígenas estuvieron dirigidas a cómo veían los europeos a los indígenas sudamericanos, qué pensaban de ellos, qué les interesaba de su cultura y una muy particular e impactante para los estudiantes europeos: si había en sus países poblaciones indígenas y cómo las trataban.

Cómo puede apreciarse en las preguntas se refleja la situación señalada anteriormente de mayor conocimiento y experiencia intercultural de parte de la población indígena respecto de la no-indígena. Los estudiantes indígenas no preguntaban cómo vivían los europeos, cuál era su cultura y su lengua, pues forma parte 
de su conocimiento general y sentido común. Al contrario, preguntaban qué sabían de ellos. Las respuestas fueron satisfactorias pues se mostraron sorprendidos por el conocimiento que tenían sobre su cultura y por el interés que mostraban. La preparación previa del grupo de estudiantes europeos fue muy importante. Y la sorpresa en relación a ese conocimiento tiene que ver con que en Brasil e incluso en el estado de Santa Catarina, parte significativa de la población ignora la existencia de poblaciones indígenas en la región sur, que suponen totalmente colonizadas por brasileros de origen europeo, una situación de invisibilización cultural propia del prejuicio colonial aún muy arraigado.

El interés, respeto, empatía y mirada positiva de parte de los estudiantes europeos fue útil en estimular la comunicación y permitir que los kaingang muestren su cultura, lengua y tradiciones. Cuando el diálogo finalizaba, ofrecieran cantar una canción tradicional en su lengua como muestra de agradecimiento y amistad. Fue el momento más emotivo de la experiencia.

Aquí las respuestas y apreciaciones de cuatro de los estudiantes kaingang respecto de la pregunta sobre cómo valoraron la experiencia, el diálogo y el intercambio con los estudiantes europeos.

Es importante estar ante una nueva experiencia, interactuar con personas que también quieren saber sobre la diversidad de otras culturas. Para mí, que soy educador, sirvió mucho como estímulo, para buscar ampliar mis conocimientos sobre otras culturas [...] Yo valoro el diálogo de extrema importancia, espero poder seguir hablando con esos estudiantes, y un día, ir a visitarlos. (ESTUDIANTE 1, Junio 15, 2019).

Me sorprendió. Me di cuenta de que no saber hablar otro idioma hace que las preguntas no estén bien elaboradas. [...] Es importante conocer gente extranjera, conocer otras historias y culturas. Así puedo trabajar con mis alumnos y hablarles de lo que conocí. (ESTUDIANTE 2, Junio 15, 2019).

Yo valoro de extrema importancia este tipo de diálogo, pues ya es hora de que los pueblos indígenas busquen nuevos mecanismos en lo referente al conocimiento, procurando llevar a las comunidades indígenas el conocimiento de otras culturas. [...] Gracias a Unochapecó fue posible conocer a esas personas. También, una de las preguntas que no pude hacer es si existe posibilidad a través de estas universidades, de desarrollar o crear proyectos de sostenibilidad para las comunidades indígenas. Pues es muy preocupante ver la llegada de la soja y del maíz transgénico en nuestras tierras y en los alrededores, pues con ellos llegan los venenos. (ESTUDIANTE 3, Junio 15, 2019).

Me sentí inseguro al hacer las preguntas, porque nosotros solemos preguntar frente a frente. Pero es una experiencia diferente, de vídeo conferencia, si puedo voy a hacerlo otras veces. [...] Cada uno tiene curiosidad en conocer la cultura del otro no. Ellos se quedaron curiosos en saber sobre nuestras mitades clánicas. Creo que un pueblo tiene mucho que aprender con el otro. (ESTUDIANTE 4, Junio 15, 2019).

Como ilustran estas respuestas la evaluación fue positiva. Además, evidencian el cumplimiento de uno de los objetivos de esta experiencia: ampliar el horizonte de la educación indígena a fin de que atienda las necesidades de la comunidad, pero no quede estrictamente limitada a ella. Los educadores indígenas son mediadores interculturales y este contacto respetuoso y empático con estudiantes de otro continente, que hablan otras lenguas es sumamente útil. Incluso ya están demandando más de estas experiencias y pensando en establecer vínculos externos que ayuden a enfrentar problemas en su comunidad como el citado problema medio ambiental. Estas experiencias enseñan y ayudan a crear y gestionar estos vínculos. Evaluamos la experiencia como altamente satisfactoria para los estudiantes indígenas.

Para los estudiantes europeos, por su parte, la conferencia fue la primera oportunidad que tuvieron de entrar en contacto directo con los indígenas americanos. Significó una ocasión óptima para comprender de manera práctica y concreta los conceptos y la historia aprendida en relación a los pueblos que sufrieron 
la conquista, colonización y aún sufren una serie de prejuicios coloniales que dificultan su desarrollo como pueblo en el nuevo contexto histórico. Pudieron preguntar directamente sobre la vida y la cultura de sus contrapartes. Y lo paradójico es que todavía más importante que las respuestas, fueron las preguntas que a ellos les realizaron. Los estudiantes europeos habían especulado sobre las respuestas que podrían recibir sus preguntas. Sin embargo, no pudieron anticipar lo que preguntarían los estudiantes kaingang. En especial una cuestión resulto totalmente inesperada y los hizo reflexionar sobre su propia cultura e identidad: la pregunta sobre si había pueblos indígenas o tribus en el Reino Unido.

Los sorprendió tanto que la encontraron difícil de responder, no porque carecieran de conocimiento, sino porque no habían considerado la historia de las Islas Británicas desde una perspectiva indígena antes de esto. Si bien el nativismo populista (FORD; GOODWIN, 2014) parece estar aumentando en el Reino Unido (y en otras partes del mundo occidental), el concepto de un verdadero pueblo indígena en las Islas Británicas no existe como en las Américas.

Requirió pensar el concepto de indigenidad en su propio contexto social y nacional. Una idea que rara vez se emplea. En ese primer momento respondieron que no había pueblos indígenas en el Reino Unido, aunque sí, agregaron, que los habitantes de Escocia e Irlanda representaban alguna semejanza con la idea de pueblo indígena. Talvez, dijeron, algunos de estos pueblos podrían considerarse cuasi-indígena.

La dificultad que enfrentaron para responder a esa cuestión dio lugar a una serie de discusiones posteriores en la que algunos estudiantes intentaron entender su propia historia desde esta nueva perspectiva. Fue un proceso importante pues creó nuevas oportunidades de entendimiento, aprendizaje, reevaluación y recomprensión de la historia británica a partir de los conceptos implícitos en la pregunta de los estudiantes kaingang. Se pudo reconsiderar la historia de las islas británicas, pensar sobre cómo las olas secuenciales de grupos humanos han afectado a las islas. El patrón histórico de asentamiento de estas poblaciones dio lugar a una red complicada y superpuesta de identidades y culturas en convivencia y/o competencia que emergen en toda la región. La población prerromana de las islas británicas (los celtas) aparecen supuestamente, al igual que los pueblos indígenas de las Américas, como pueblos "sin identidad". En Inglaterra, los romanos, los anglos, los jutes, los sajones y los vikingos desplazados, se fusionaron o dominaron a la población celta, lo que dio como resultado una cultura altamente dinámica que evolucionó constantemente y que integró elementos culturales significativos de cada uno de estos grupos. En algunas partes de Escocia e Irlanda, sin embargo, estas oleadas tuvieron menos impacto. Esto llevó a que las regiones menos afectadas como las tierras altas de Escocia y grandes partes de Irlanda y Gales, conserven un sentido distinto de identidad y, en algunos casos, el idioma y la idea de una pertenencia cultural diferenciada (TRILLING, 2012).

El diálogo con los estudiantes indígenas impulsó a reconsiderar la propia historia desde una perspectiva distinta y a alcanzar otra comprensión del papel desempeñado por la inmigración, la integración de la población y la existencia de identidades distintas dentro del propio contexto histórico y nacional. Un fenómeno que era abstracto y lejano se volvió sumamente relevante a partir de una mirada con distinta perspectiva, la perspectiva indígena que de otro modo no habría surgido en el módulo.

Esta circunstancia muestra el valor de la experiencia de diálogo intercultural con voces no occidentales pocas veces escuchadas. Para un grupo de estudiantes con aspiraciones de carrera que van de la obtención de doctorados en historia indígena hasta trabajar para las Naciones Unidas o una variedad de ONG, esta experiencia tuvo un valor enorme. Demostró la importancia de crear situaciones de diálogo 
en las que se hacen preguntas, pero en las que también hay que elaborar respuestas a cuestiones a veces inesperadas. Proporciona la oportunidad e incluso requiere que un individuo reevalúe el marco que utiliza para entenderse a sí mismo y su relación con otras culturas.

A través de las discusiones que siguieron a la sesión, quedó claro que los estudiantes europeos comprendieron que no solo tuvieron la oportunidad de aprender sobre los kaingang, sino además la oportunidad de aprender sobre ellos mismos.

\section{Conclusiones}

La conclusión más relevante de este trabajo es que muestra que es posible construir espacios reales y concretos de diálogo intercultural respetuoso, empático, horizontal que sirvan para reorganizar en el mundo las relaciones entre culturas en base a la cooperación y de comunicación solidarias entre los diferentes universos culturales existentes en la humanidad.

La segunda conclusión importante es que prueba que el ámbito educativo es un espacio sumamente importante donde se puede construir este diálogo. Es más, creemos que la escuela indígena puede pensar en sí misma como un espacio de diálogo entre culturas, donde se medían saberes, creencias, formas de ser, estar y pensar el mundo. La escuela indígena debe ser parte sustancial del mundo donde quepan muchos mundos.

Este estudio no permite llegar a una tercera conclusión relevante basados en la experiencia de los estudiantes europeos: no solo la escuela y la educación indígena puede ser entendida como un espacio de diálogo intercultural. La escuela y la educación sin más en una sociedad abierta y democrática en este momento histórico de comunicación y contacto cultural intenso puede convertirse en un espacio de diálogo intercultural. El impacto en los estudiantes europeos, la reelavoración de sus ideas sobre los otros y sobre sí mismos muestra que además de posible, esto es también deseable.
Para finalizar afirmamos que los objetivos de la experiencia fueron alcanzados, ambos grupos evaluaron como sumamente positivo el impacto de la experiencia, ambos grupos tuvieron la oportunidad de aprender de otra cultura. Además, de estos aprendizajes obtuvieron experiencia directa al participar y administrar un espacio intercultural dinámico e intelectualmente fructífero que pueden replicar en sus carreras profesionales después de su graduación en los diversos ámbitos en que se desarrollen. Todos aprendimos que un mundo donde quepan muchos mundos, es posible.

\section{REFERENCIAS}

BLANCO, M. Autoetnografía: una forma narrativa de generación de conocimientos. Andamios Revista de Investigación Social, Ciudad de México, v. 9, n. 19, p. 49-74, 2012.

FORD, R.; GOODWIN M. Revolt on the right: explaining support for the radical right in Britain. London: Routledge, 2014.

FORNET-BETANCOURT, R. Supuestos filosóficos del diálogo intercultural. Revista Polylog, n. 1, 2000. Disponible en: http://them.polylog.org/1/ffr-es. htm. Acesso en: 05 feb. 2019.

FUNDAÇÃO NACIONAL DO ÍNDIO (FUNAI). O Brasil indígena. Brasília, $D F, 2010$.

KEEPERS OF THE FOREST: A TRIBE OF THE AMAZON IN THE MODERN WORLD (HISTORY \& CULTURE OF THE KAINGANG). Dirección: Daren Reid. Studio Academe, 2019. Disponible en: https://www. youtube.com/watch?v=ZywE92bDCrQ\&t=698s. Acesso en: 05 feb. 2019.

SANTOS, J. A.; PIOVENZANA, L.; NARCISO, A. Propuesta de una metodología intercultural para una pedagogía indígena: la experiencia de las licenciaturas interculturales indígenas con el pueblo Kaingang. Revista Brasileira de Estudos Pedagógicos, Brasília, DF, v. 99, n. 251, p. 189-204, 2018.

SANTOS, J. A.; BATTESTIN C.; PIOVENZANA, L. Paradojas interculturales en la formación de profesores indígenas del pueblo Kaingang. Revista Díalogo Educacional. v. 18, n. 59, p. 1222-1241, 2018.

SANTOS, J. A. Aportes para una pedagogía crítica nuestroamericana: identificando el núcleo con- 
ceptual del pensamiento político-pedagógico de Paulo Freire. Revista Pedagógica, v. 9, n. 41, p. 80-95, 2017.

MINAYO, M. C.; GOMES, R.; DESLANDES, S. F. Pesquisa Social: teoria, método e criatividade. Petrópolis, RJ: Vozes, 2002.

PUIGGRÓS, A. Presencias y ausencia en la historiografía pedagógica latinoamericana. En: CUCUZZA, H. (comp.). Historia de la educación en debate. Buenos Aires: Ed. Miño y Dávila, 1996. p. 91-119.

PANIKKAR, R. Paz e interculturalidad: una reflexión filosófica. Barcelona: Herder, 2006.

TRILLING, D. Bloody nasty people: the rise of Britain's far right. London: Verso, 2012.
VEIGA, J. Cosmologia e práticas rituais Kaingang. 2000. 367 f. Tese (Doutorado em Antropologia Social) - Instituto de Filosofia e Ciências Humanas da Universidade Estadual de Campinas (Unicamp), Campinas SP, 2000.

VEIGA, J. Organização social e cosmovisão Kaingang: uma introdução ao parentesco, casamento e nominação em uma sociedade Jê meridional. 1994. 282 f. Dissertação (Mestrado em Antropologia Social) - Instituto de Filosofia e Ciências Humanas da Universidade Estadual de Campinas (Unicamp), Campinas, SP, 1994.

Recebido em: 11/06/2019

Aprovado em: 14/11/2019 